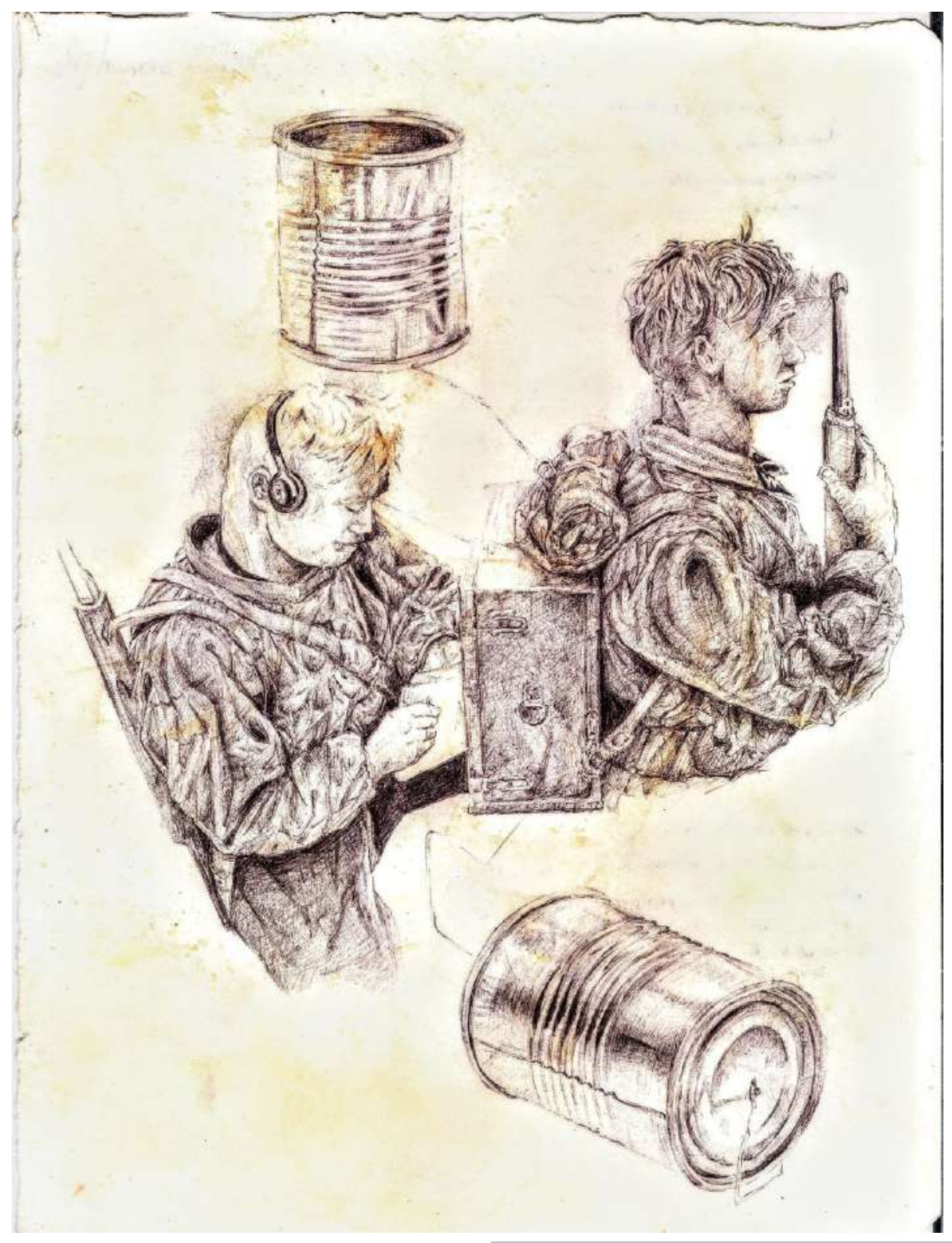

Sebastián Zea Quintero

Sin título

De la serie Del juego y el hombre Lápiz sobre papel 2017

Medellín 


\title{
Resignificación de política y poder en el discurso del Movimiento Zapatista*
}

\author{
Aldo Juan Meneses Carvajal (Chile)** \\ Javier Castillo Reyes (Chile) $)^{* * *}$
}

\section{Resumen}

Este artículo tiene como objetivo mostrar cómo la ética discursiva del Movimiento Zapatista resignifica las nociones tradicionales de poder y política. Se aborda a través de una revisión sobre el discurso Zapatista, cuyos planteamientos se comprenden a partir de una perspectiva normativa, comunitarista y crítica, pues este genera instituciones que legitiman su accionar, ocupando como principio deontológico el «mandar obedeciendo». Este principio resignifica las nociones de política y poder que configuran la emergencia de un sujeto como productorproducido en las organizaciones, al poner en cuestión la paradoja del individuo determinado por la estructura o si es este quien la determina. Así, se pueden constatar cambios estructurales dentro un territorio determinado, modificados desde lo discursivo y no necesariamente apropiándose de lugares que representan al poder, como el Estado. Esta producción discursiva permite que el poder sea visto

[ 46 ] desde una representación horizontal y no jerárquica, entendiendo la política como un lugar inclusivo, diverso y heterogéneo.

\section{Palabras clave}

Teoría Política; Comunicación Política; Análisis del Discurso; Movimiento Zapatista; Mandar Obedeciendo.

Fecha de recepción: junio de 2019

- $\quad$ Fecha de aprobación: febrero de 2020

\section{Cómo citar este artículo}

Meneses, Aldo Juan y Castillo, Javier. (2020). Resignificación de política y poder en el discurso del Movimiento Zapatista. Estudios Políticos (Universidad de Antioquia), 58. pp. 46-65. DOI: 10.17533/udea.espo.n58a03

\footnotetext{
* Este artículo se deriva de la investigación de Javier Castillo para optar al título de Cientista Político en la Universidad Central de Chile, bajo la dirección del profesor Aldo Meneses.

** Psicólogo. Magíster en Psicología. Magíster y doctor en Sociología. Posdoctorado en Psicosociología de las Organizaciones. Profesor asociado del Instituto de Asuntos Públicos, Universidad de Chile. Correo electrónico: ameneses@iap.uchile.cl

** Cientista Político. Diplomado en América Latina, Desarollo y Cultura: Los Desafíos de la Globalización. Estudiante de maestría en Psicología. Correo electrónico: jacasre@gmail.com
} 


\title{
Redefinition of Politics and Power in the Discourse of the Zapatista Movement
}

\begin{abstract}
This paper aims at unveiling how the discursive ethics of the Zapatista Movement redefines the traditional notions of power and politics. This is addressed from discourse theory, understanding Zapatista approaches from a normative, communitarian and critical perspective, given that their discourse generates institutions which legitimize their praxis using «Commanding-Obeying» as a deontological principle. This principle redefines the notions of politics and power, shaping the emergence of a producer-produced subject within the organizations, an outcome that challenges the dichotomy between an individual determined by the structure and individuals determining structures. Therefore, we are able to find structural changes in a specific territory, stemming from discourse and not necessarily appropriating places representing power as the State. This discursive production allow us to see power as an horizontal and non hierarchical concept and politics as an inclusive, diverse and heterogeneous space.
\end{abstract}

\section{Keywords}

Political Theory; Political Communication; Discourse Analysis; Zapatista Movement; Ordering/Obeying. 


\section{Introducción}

Este artículo tiene como objetivo dar a conocer el quiebre en torno a la noción hegemónica de poder y política a través del discurso sobre el Movimiento Zapatista, luego de su irrupción el 1. de enero de 1994 en el estado de Chiapas, al sureste de México, a partir del estudio del discurso sobre los zapatistas, de sus entrevistas y de variadas apariciones públicas, así como de sus singulares formas de organización que rebasan los patrones comunes del quehacer político dominante, evidenciando de esta forma el poder constitutivo de realidad de las producciones discursivas. Por ello se analiza la institucionalidad del movimiento, destacando que en 2003 se crearon las Juntas del Buen Gobierno (JBG) y los «Caracoles» como mecanismos institucionales que aportan a la autonomía y autogestión, mostrándose como una alternativa paralela frente al sistema político mexicano. Interesa destacar que el accionar del Movimiento Zapatista, tanto en su producción discursiva como en su praxis - JBG y Caracoles-, ha fundado una fractura significativa al delimitar lo que se puede entender por política y poder en el campo de las ciencias sociales y en su práctica.

Las JBG y los Caracoles funcionan con base en el principio de «mandar [ 48 ] obedeciendo», el cual rompe con cualquier definición tradicional de poder desarrollada por las ciencias sociales y, en especial, por la ciencia política, que descansan en las nociones de mando-obediencia, vinculando a la política como una actividad asimétrica y excluyente. Por consiguiente, en su accionar se pone en cuestión las nociones habituales de poder y política —en su sentido vertical-. Así, el Movimiento Zapatista diluye la forma asimétrica que adquiere el poder en su definición predominante, como un objeto que se puede utilizar y manipular para ciertos fines, pues ellos dejan de lado la reificación del poder al generar una política incluyente que sostiene que su lucha política es por la humanidad y la dignidad como un valor transversal, mostrando con ello su impronta como movimiento social.

En sus aspectos metodológicos, este trabajo realiza una revisión sobre el discurso del Movimiento Zapatista, circunscribiéndose dentro del enfoque de análisis crítico del discurso, pues este es importante para esclarecer de mejor forma la lucha política entablada, ya que por sus características discursivas serán de gran ayuda para comprender el «entendimiento de las relaciones entre el discurso y la sociedad, en general, y de la reproducción del poder social y la desigualdad» (Van Dijk. 2009, p. 152). 
Se utilizó la teoría normativa en su vertiente comunitarista como herramienta de reflexión, pues como señala Isaiah Berlin, esta consiste en «el descubrimiento o la aplicación de principios morales a la esfera de las relaciones políticas» (citado en Marsh y Stoker, 1997, p. 33). Aquello nos permite un mejor análisis sobre los discursos realizados por el Movimiento Zapatista, ya que observa su componente inclusivo y heterogéneo, facilitando una mejor explicación del tema, pues allí se puede observar su fuerte carácter deontológico.

En este artículo se refieren algunas características del movimiento zapatista en sus aspectos estructurales, la práctica discursiva del zapatismo en tanto productora de realidad social y la resignificación que el discurso zapatista realiza de la ética-política y del poder, para luego poner en evidencia la eficacia práctica del discurso que logran plasmar estas nuevas significaciones en la institucionalidad de las llamadas Juntas de Buen Gobierno y los Caracoles. Se trata, en definitiva, de poner en evidencia la capacidad discursiva para promover comportamientos a partir de la representación de la realidad que comprenden sus contenidos, colocando de manifiesto la «eficacia de lo simbólico» (Ansart, 1983).

\section{Articulación y construcción del Movimiento Zapatista}

Dentro de la comprensión de los movimientos sociales, se debe entender al Movimiento Zapatista como un «conjunto de luchas erigidas contra el capitalismo y en función de la construcción de un mundo más justo, más humano y solidario que se dan en un período y en un espacio determinado» (Parra, 2005, p.73). El Ejército Zapatista de Liberación Nacional (EZLN) comenzó a organizarse aproximadamente en 1984 y ve la luz social el 1. de enero de 1994 al ocupar San Cristóbal de las Casas, Altamirano, Las Margaritas, Ocosingo, Oxchuc, Huixtan y Chanal, proclamándose como el resultado de quinientos años de lucha, aludiendo a la llegada del hombre blanco al «Nuevo Mundo». Precisamente, su emergencia en esa fecha en contra del Estado mexicano se debió a la «entrada en vigor del Tratado de Libre Comercio y el inicio del año electoral [donde] exigen la renuncia del gobierno federal y estatal y que se convoque a elecciones libres y democráticas» (Zapatista Organización, 2014, 28 de noviembre). 
La irrupción en Chiapas tiene un gran significado simbólico que los lleva a dividir sus demandas en «once aspectos básicos: trabajo, tierra, techo, alimentación, salud, educación, independencia, libertad, democracia, justicia y paz» (Martínez, 2006, p. 3), debido a que Chiapas se encontraba en circunstancias de «altos niveles de pobreza, marginación y desigualdad entre la mayoría de sus habitantes» (p. 4), generalmente indígenas. No obstante, el Movimiento Zapatista constata una diversidad de elementos coyunturales, históricos y estructurales derivados de su contexto nacional, local e internacional (Martínez, 2007), que a través de su retórica discursiva abarca un todo colectivo, forjando la construcción de la revolución a través de las palabras, dándole mayor connotación a los significados de los acontecimientos y hechos históricos.

En este sentido, la naturaleza de este movimiento se vincula con la Revolución Mexicana de 1910, por su carácter agrario y sus reivindicaciones democráticas; además, por posicionarse desde la resistencia, ya que su constante discursiva se manifiesta en el sentimiento del deber de reescribir la historia. Es así que a través de la retórica el movimiento comienza a hacerse público, suscitando un gran apoyo mundial, pues más allá de ser un grupo armado, ha sido capaz de construir una identidad por medio de las palabras vinculadas con la injusta realidad de los chiapanecos en ese momento, situación compartida con otros pueblos que con la consecuente explotación de tierras ha provocado mayores desigualdades en distintos territorios, por lo que quienes conforman este movimiento no son solo indígenas, sino que también participan la sociedad civil nacional e internacional, y algunos países europeos y latinoamericanos que simpatizan y se adhieren a su movimiento. Su crítica al modelo neoliberal actúa a la vez como principio de totalidad (Touraine, 1995, p. 251), propio de un movimiento social, al condensar en dicho discurso una transversalidad colectiva opuesta a la práctica discursiva de un grupo sectorial.

De acuerdo a lo anterior, se considera también un movimiento social porque integra en su discurso a diversos sectores históricamente excluidos. De ahí que el Movimiento Zapatista posee la fisonomía de una revolución histórica de hace ya un siglo y surge también en el contexto de las guerrillas latinoamericanas que se dieron en la segunda mitad del siglo xx. Sin embargo, su diferencia radica en que prioriza las estrategias discursivas por sobre las armadas. 


\section{El discurso zapatista como elemento constitutivo de la realidad}

Una de las principales armas que utiliza el Movimiento Zapatista para llevar a cabo sus propuestas y propósitos es el discurso. Su práctica discursiva resulta relevante a la hora de interpelar los símbolos del lenguaje que permean la semántica dominante de las palabras en uso, estructurando así una realidad que por esta vía se muestra como incuestionable. Con ello, la carga afectiva propia del orden simbólico promueve o desalienta determinados comportamientos. De esta forma, analizar al Movimiento Zapatista a partir del discurso nos aproxima a sus planteamientos, puesto que «como ningún otro movimiento social y/o clandestino conocido, la experiencia viva zapatista comprueba la veracidad de la premisa básica de un tratamiento analítico de lo discursivo: que el decir es una forma de hacer» (Huffschmid, 2009, pp. 85-86).

El zapatismo ha sido capaz de utilizar ciertas funciones lingüísticas para la regeneración y construcción de la realidad, pues como lo indica John Holloway (2011), siguiendo a Marx, «el hacer humano implica proyección más allá y, por lo tanto, unidad de teoría y de práctica» (p. 45). En este sentido, el hacer se encuentra estrechamente vinculado con la producción discursiva, es decir, como una proyección propia del enunciante. La palabra se torna un elemento clave para cuestionar la realidad, pero también se vuelve un componente fundamental para la creación de otras formas de vida social acalladas por el discurso dominante - haciendo referencia al neoliberalismo y al capitalismoDe ahí que «cualquier desviación radical que se aparte del orden institucional aparece como una desviación de la realidad, y puede llamársela depravación moral, enfermedad mental, o ignorancia» (Berger y Luckmann, 1998, p. 89), coartando con ello alternativas a lo definido como realidad oficial.

Asimismo, y para remarcar la importancia del lenguaje, el Subcomandante Marcos señala que: «desde aquella madrugada del inicio del 94, hemos dedicado, primero con el fuego y luego con la palabra, nuestra lucha, nuestro esfuerzo, nuestra vida y nuestra muerte, [...] al reconocimiento de sus derechos y su cultura» (EZLN, 2005, junio 21). En consecuencia, el valor que le otorgan los zapatistas al discurso y al lenguaje, especialmente en su dimensión simbólica, es de suma importancia, ${ }^{1}$ ya que la palabra es

\footnotetext{
${ }^{1}$ De esta forma, el lenguaje aparece claramente como una categoría ontológica, es decir, algo constitutivo propiamente del ser y que le es inmanente (Tomassini, 2010).
} 
un factor determinante para su lucha. Como le señala el subcomandante Marcos a Guadalupe Loaeza: «viera usted qué buena es esta arma. Es buena para combatir, para defenderse, para resistir. Y tiene una ventaja sobre todas las armas que tiene el gobierno, sean sus militares y paramilitares, ésta no destruye, no mata» (citado en Hernández, 2002, p. 113).

El zapatismo provoca un discurso que resquebraja el statu quo defendido por quienes promueven el neoliberalismo y lo avalan bajo los sistemas democráticos-liberales actuales, en especial en México. Se puede asumir que este es un:

Discurso que subvierte y ataca, al estilo de la guerrilla, determinados esquemas del pensamiento político [...] al conectarse de una manera específica (explorable) con las semánticas culturales y mitológicas modernas en el contexto de una globalización comunicativa y simbólica, a la vez que desconectándose de los repertorios clásicos de la revolución [...] o de los tópicos más comúnmente asociados con lo indígena (folclore, miseria pasiva, separatismo étnico) (Huffschmid, 2009, p. 86).

Se puede apreciar que la lucha zapatista utiliza el discurso como [ 52 ] herramienta para generar cambios y exigir demandas, lo que lo convierte en un movimiento social singular en relación con otros. Sin embargo, para comenzar a realizar una aproximación sobre el discurso político del Movimiento Zapatista es necesario abordarlo a partir de las concepciones establecidas por Jean-Baptiste Marcellesi, Ferruccio Rossi-Landi y Oliver Reboul (Hernández, 2002): «los tres autores están de acuerdo en que son inseparables política e ideología y que ésta se plasma en un discurso» (p. 101), aunque se debe tener en cuenta que cada autor propone ciertas características distintas entre sí.

Por un lado, Rossi-Landi afirma que «un discurso revolucionario [...] se distingue de los otros discursos ideológicos porque se reconoce como tal y porque recurre a un privilegio no ya extra-histórico sino infra-histórico, o sea fundado en el futuro» (Hernández, 2002, p. 102). Por ello el discurso político revolucionario tiene un componente asociado a la construcción de algo nuevo, para lo cual es indispensable modificar la situación actual: «Para Rossi-Landi la validez racional y, por tanto, revolucionaria de un discurso, está en su relación con lo histórico; de ahí que reaccionario implique afincarse estáticamente en el pasado, disociando así conciencia y praxis, y revolucionario en proyectarse de manera dinámica hacia el futuro» (p. 102). 
Marcellesi distingue una lectura ideológica de otra política, donde el discurso político «es fruto de una situación que se caracteriza por el hecho de que quien enuncia espera que su auditorio haga una lectura política de su discurso, mientras que la lectura ideológica, abarca la totalidad del discurso» (Hernández, 2002, p. 102). En concordancia, el discurso político «se fundamenta en la presentación de dos formas retóricas articuladas: una didáctica, cuyo fin es persuadir al oyente de que sus argumentos son verdades universales [...]. Y otra polémica con dos aspectos, uno en el que se refuta las afirmaciones de un adversario, y otro en el que presenta tales afirmaciones como opuestas a las suyas» (p. 102).

Por su parte, para Oliver Reboul «la relación entre ideología y discurso está mediada por la racionalización que legitima el poder en su discurso. [...] el poder no es sólo poder del Estado, lo importante es que la ideología se apoya sobre un poder y ella misma es, entonces, un poder, ya que transforma la fuerza en derecho y la obediencia en deber» (Hernández, 2002, p. 103), por lo que la ideología mediante el discurso estructura patrones de comportamiento que son entendidos como los veraces, de ahí que cualquier otra forma de conducta que desborde los modelos implementados por los esquemas ideológicos apoyados sobre dicho poder es considerada como algo que «atenta contra el poder» (p. 103): «el discurso político se construye en efecto sobre el modo de un discurso moral, él opone fines legítimos y males que evitar, buenos y malos objetos» (Ansart citado en Lazo, 2004, p. 172), lo cual denota el deber arbitrario generado por cualquier tipo de discurso político, en específico, el del discurso dominante:

Lo que caracteriza a lo ideológico es la violencia, pero ésta se justifica y se enmascara en su racionalidad, que en un nivel profano permite la discusión de las ideas en el marco de la coexistencia, en tanto establece un límite sagrado que no se puede transgredir, no permite que la discusión de las ideas rebase el espacio que su poder autoriza (Hernández, 2002, p. 103).

Por ende, el ámbito profano aporta un necesario espacio en el cual se pueden debatir y discutir ideas, sin embargo, la ideología neoliberal y el capitalismo en general han reducido los espacios que puedan generar múltiples formas de vida y diversas identidades, siendo menester recordar que la lucha zapatista, además de ser heterogénea, también lo es universal: 
El impacto planetario y la universalidad de este movimiento no pueden comprenderse si se le reduce a la resistencia de algunas comunidades de Chiapas, o a otro sobresalto de la historia mexicana reciente. [...] El zapatismo no supone un repliegue comunitario ni un nacionalismo cerrado. Articula experiencias de comunidades heterogéneas, divididas y abiertas; la democracia nacional y el proyecto de una sociedad de sujetos, individuales y colectivos, que se reconozcan y puedan respetarse en su diversidad; lucha por un mundo donde quepan muchos mundos, un mundo que sea uno y diverso (Subcomandante Marcos y Le Bot, 1997, p. 7).

El discurso zapatista se puede enfocar en un sentido polémico bajo la concepción del discurso político de Marcellesi, pues este reclama contra la universalidad del proyecto político moderno que intenta homogeneizar y colonizar las conductas de las personas, tratando de borrar las singularidades de los individuos y sujetos colectivos, pues justamente es esa forma moderna de universalidad la que critica el zapatismo, ya que su lucha universal apuesta por algo mucho más elevado, es decir, apuesta por la humanidad y la dignidad del ser humano. Esto se puede entender considerando que la modernidad es un proyecto totalizante que ha tenido como objetivo promover la uniformidad del pensamiento, subordinando lo particular a lo general: «El Proyecto de Modernidad tuvo como ideas guía: [...] una razón universal como orden cósmico accesible a la conciencia racional, y la suposición de que un sujeto centrado y central, activo y responsable. La Modernidad ha defendido la idea del progreso como proceso lineal, irreversible y necesario» (Firedmann, 2010, pp. 4-5).

De suyo, se puede establecer que todo lo que escapa de la razón se encuentra fuera de lugar, pues lo que se necesita es una certidumbre que permita controlar y clausurar la realidad, que todo lo que se establezca tenga lógica y coherencia. Es por ello que para encajar en este rompecabezas lo que se necesitan son respuestas creíbles y controlables. En sentido contrario, el EZLN tiene como virtud:

Reconocer que no tenía respuesta y que debía aprender. Ésta es la primera derrota del EZLN, la más importante y la que lo marcará de ahí en adelante. Cuando el EZLN se enfrenta a algo nuevo y reconoce que no tiene solución para ese problema que tiene que esperar y aprender, deja de ser maestro. Lo único que puede aportar ante esa realidad es un montón de preguntas, pero ninguna respuesta (Subcomandante Marcos y Le Bot, 1997, pp. 62-63). 
Esto último resulta interesante puesto que todo discurso dominante genera certezas y no vacilaciones que van constituyendo un «saber» que legitima una forma de hacer las cosas, de establecer y justificar un orden imperante. Dicha legitimación justifica el orden institucional, adjudicando dignidad normativa a sus imperativos prácticos, así la legitimación tiene un elemento tanto cognoscitivo como normativo. En otras palabras, la legitimación no es solo cuestión de «valores»: implica también «conocimiento» (Berger y Luckmann, 1998, p. 122). De esta manera, al justificar el orden institucional se aminoran las posibilidades de construir otras realidades, ya que además afecta directamente las subjetividades, Ilegando a condicionar sus propios sueños, de ahí que el lenguaje sea fundamental para explicar y justificar el proceso de institucionalización, pues este «se convierte en base e instrumento del acopio colectivo del sujeto» (p. 91).

En efecto, se puede deducir que el camino recorrido por el Movimiento Zapatista ha sido en torno a un constante aprendizaje, que siempre permite su reconfiguración y la creación de nuevas formas de combatir, sin perder de vista que la base de su movimiento se articula en la batalla contra el neoliberalismo y a favor de la humanidad y de la dignidad, lo cual se plasma en las palabras del comandante Tacho, al recalcar que «hacer la revolución [...] es como ir a clases en una escuela que todavía no está construida» (citado en Holloway, 2001, p. 175).

\section{3. Ética, política y revolución en la significación zapatista}

Retomando lo expuesto por Reboul, para acercarse a una comprensión discursiva de la praxis zapatista se distinguen dos tipos de ideologías:

Por un lado se hablará de la existencia de una ideología «difusa (al servicio del poder) y otra sectaria (contra una forma de poder)», [en cuanto que la segunda] acentúa el efecto de tensión entre el contexto y la figura, pues «de esa tensión nacen lo cómico del juego de palabras, la poesía de la metáfora, el sarcasmo de la ironía» (Hernández, 2002, p. 104).

En torno a los lineamentos expuestos con base en Rossi-Landi, Marcellesi y Reboul se puede constatar que el discurso zapatista contiene varios componentes de los elementos señalados por estos autores. Sin embargo, hay que mencionar que no todos los elementos constituyen la totalidad de dicho discurso, pues en algunos aspectos se asemeja, pero en otro se aleja. 
Es así como el discurso zapatista en particular, por medio de una de sus figuras más emblemáticas, el subcomandante Marcos, pertenece a lo que Rossi-Landi denomina discurso revolucionario, «puesto que se proyecta hacia el futuro, sin embargo, la tesis del filósofo italiano no cuadra del todo con dicho discurso, en tanto su proyección al futuro se apoya en la reivindicación de un pasado indígena que ha sido silenciado por el discurso del poder establecido» (Hernández, 2002, p. 104). Ello se aprecia muchas veces cuando el discurso zapatista se articula con la memoria, apelando a la figura de Emiliano Zapata, haciendo alusión a lo ocurrido en la revolución mexicana, como ejemplo de un levantamiento en contra de la exclusión y del sometimiento, de ahí que estos resalten que son los «herederos de Zapata»; además de esto, se incorpora y articula como elemento esencial el componente indígena, al establecer en la Primera Declaración de la Selva Lacandona (1994), que ellos son «producto de quinientos años de lucha: primero contra la esclavitud, en la guerra de Independencia contra España encabezada por los insurgentes, después por evitar ser absorbidos por el expansionismo norteamericano» (EZLN, 2005, junio 21).

De esta manera, los quinientos años reflejan lo ocurrido desde la dominación y explotación de Occidente hacia el continente latinoamericano, mediante la llegada de Colón al supuesto «Nuevo Mundo»; sin embargo, se debe acotar que el zapatismo se encuentra ligado «a la necesidad de defenderse en contra de la explotación y al deseo de alcanzar un futuro en el que gocen de mejores condiciones de vida» (Leyva, 1999, p. 8). Paralelamente, el discurso emanado del zapatismo y en especial centrado en la persona del subcomandante Marcos se relaciona con lo que «Reboul llama una ideología sectaria que usa el lenguaje connotativo para construir un discurso que se contraponga al oficial —en términos de oposición — entre un discurso político mentiroso o hipócrita que se presenta como aquel que posee la certeza de la racionalidad y uno utópico que pone lo ético por encima de lo político» (Hernández, 2002, p. 104).

El discurso zapatista tiene como principal énfasis centrarse en la dignidad, lo cual se vincula a una perspectiva moral, debido a que lo que se pretende generar es un «deber ser». Es por esto mismo que rompe los esquemas de la política moderna tradicional, al instalarla con propiedad específicamente en el campo de la ética, puesto que usualmente desde Maquiavelo «la razón política se mueve en una esfera amoral, donde lo malo y lo bueno están subordinados a la ejecución de la obra política» (Godoy, 1994, p. 394), es 
decir, el campo de la política no puede ser juzgada con la misma óptica ética con la que se juzgan los actos cotidianos o sociales, en tanto que esta se piensa como una esfera autónoma. En contraste con aquello, la praxis discursiva del zapatismo no se remite a un acto meramente descriptivo de la política, sino que comporta un compromiso que prescribe, que es en sí mismo normativo, esto se aprecia con claridad en el principio de «mandar obedeciendo». En cuanto a lo trazado por Marcellesi: «el discurso de Marcos [...] cumple con los dos planos: el pedagógico, pues la presencia de los mitos antiguos mayas tiene como función cambiar nuestra manera de ver —entender- el mundo; y otro polémico, que se presenta bajo la forma de la sátira en la que ridiculiza tanto al discurso oficial en su pobreza moral como a sus voceros» (Hernández, 2002, p. 105).

Es ahí donde el discurso zapatista da un vuelco significativo a la manera tradicional de entender los fenómenos políticos, ya que su producción discursiva vincula directamente el componente ético y la narrativa de sus ancestros, es decir, los mayas, lo cual pone en suspenso la forma tradicional del acontecer político moderno. Los zapatistas «llegaron como gente prehistórica saliendo de sus cuevas, hablando de dignidad y humanidad» (Holloway, 2001, p. 172), algo extravagante para la dinámica política de la democracia liberal, que por lo demás piensa la política bajo el alero de un mercado racional entre ciudadanos-consumidores y políticos-ofertantes, ya que su praxis conlleva un profundo componente ético, en tanto que pretenden transformar la realidad que los oprime por una liberadora:

Y aquí está la paradoja de la guerra zapatista: si perdemos, ganamos; y si ganamos, ganamos. La clave está en que la nuestra es una guerra que no pretende destruir al contrario en el sentido clásico.

Es una guerra que trata de anular el terreno de su realización y las posibilidades de los contrincantes (nosotros incluidos).

Es una guerra para dejar de ser lo que ahora somos y así ser lo que debemos ser (EZLN, 2011, enero-febrero).

De esta forma se puede establecer que mediante el discurso los zapatistas han logrado un acto revolucionario, puesto que la palabra cobra relevancia para generar transformaciones que permiten pensar lo impensado, pero que también logran posicionar a quienes han sido acallados durante siglos. Es así como el discurso zapatista ha sorteado la exclusión y marginación 
que producen los discursos dominantes que han actuado históricamente en Latinoamérica, en especial hacia los pueblos indígenas. Por esto mismo el Movimiento Zapatista es significativo en comparación a otros movimientos sociales de la región, ya que ha logrado poner en tela de juicio los patrones culturales que se presentan como veraces, abriendo paso a la generación de nuevos símbolos y logrando un fuerte posicionamiento de aquellos que habían sido excluidos durante quinientos años.

En consecuencia, además de lo expuesto, es importante apreciar que otras de las características que ayudan a que este movimiento sea singular es la práctica que ha realizado en torno a cómo se pueden realizar los cambios estructurales, puesto que el zapatismo se ha alejado de las visiones clásicas de revolución, en particular de las que se vinculan a las teorías clásicas de izquierda, lo cual no quiere decir que se desvinculen por completo de estas corrientes:

El zapatismo es el intento de rescatar la revolución de los escombros de la historia, pero el concepto de revolución que emerge de estos escombros sólo puede tener sentido si es un concepto nuevo [...] la lucha política se ve a sí misma desnuda de los ropajes oxidados que le heredó el dolor, es la esperanza la que la obliga a buscar nuevas formas de lucha, es decir nuevas formas de ser políticos, de hacer política (Holloway, 2001, p. 173).

Así, además de introducir una nueva forma de establecer lo que se entiende tradicionalmente por hacer la revolución, también producen un cambio en la manera de entender la política: «el gran aporte de los zapatistas ha sido romper el vínculo entre revolución y control del Estado [...]. Tenemos que pensar en la revolución de otra manera. Tenemos que romper la identificación de la revolución con la toma del Estado» (p. 174). Esto se puede entender como que el Estado no es precisamente el centro del poder, es decir, no es el destinatario exclusivo de este:

El Estado no es el lugar privilegiado del poder; su poder es un efecto de conjunto. Hay que atender a la microfísíca del poder: a sus hogares moleculares. Este espejismo del Estado vehicula, por lo menos dos grandes errores políticos: a) plantear la toma del Estado como toma del poder; b) plantear un contra-Estado (El Partido, el Sindicato) como forma óptima de ejercicio del poder (Foucault, 2008, p. 10). 
Efectivamente, el discurso sobre el Movimiento Zapatista se vincula con lo señalado, debido a que no atiende al Estado como el elemento central para ejercer el poder; más bien, los zapatistas, por medio de sus prácticas discursivas, ejercen una manera de resistencia al poder tradicional, ya que su forma de organización expresa una alternativa a la democracia liberal y al modelo económico neoliberal.

De esta manera, la peculiaridad de los zapatistas reside en el empleo de la palabra como herramienta que promueve transformaciones sociopolíticas, en contraposición a la tradicional forma de concebir la revolución frente a los clásicos paradigmas revolucionarios. Así, el discurso zapatista «es un acto poético, una poiesis, donde la palabra se concibe como el acto fundacional de una revolución que, antes que hacer pura política, trabaja en pos de una ética. Su lucha no es por el poder político, sino por la dignidad de la palabra» (Hernández, 2002, p. 106). Dicho de otro modo, la forma de modificar los paradigmas se realiza mediante el discurso producido por ellos mismos, sin necesidad de emplear la violencia física, ni mucho menos transformándose en un actor tradicional del sistema político democrático. Por ende, se debe destacar que el zapatismo denuncia el abuso del poder a través de la palabra como herramienta y arma principal, transformando mediante ella la realidad, creando nuevos símbolos perdurables que tensionan lo instituido y dialogan con otras formas resistencia

Es así como la retórica de los zapatistas ha sido significativa para derribar muros y hacerse conocidos, ya que han planteado una variedad de desafíos al dejar un cúmulo de interrogantes sobre el funcionamiento político, social y económico de los gobiernos actuales, dejando entrever las enormes fisuras que el sistema ha provocado. Desde esta perspectiva, se puede plantear que la rebelión zapatista ha poseído durante toda su trayectoria un carácter discursivo estructural o dimensión semántica.

\section{Las Juntas de Buen Gobierno y los Caracoles: una institucionalidad paralela al sistema político mexicano}

La Juntas de Buen Gobierno (JBG) y los Caracoles se crearon en 2003 como dos formas de organización sui generis del Movimiento Zapatista para generar una institucionalidad que pueda otorgar mayor autonomía y resistencia al movimiento, y que reafirme su legitimidad, aun cuando en los ámbitos nacional e internacional la posea. Dichas instituciones 
representan un punto de inflexión para el movimiento, ya que dentro de ellas se logran plasmar algunos de sus principios y su relevancia reside en tres propiedades principales:

1) es un tema que se vincula con otros (movilizaciones políticas, instituciones informales, politización de lo indígena) ...]; 2) las JBG y los Caracoles son instituciones creadas por un movimiento político que no tienen total cabida en el marco legal mexicano, $[\ldots]$; 3) en las JBG y los Caracoles se gestan procesos políticos-sociales relacionados con aspectos tales como la democracia, el desarrollo social y la práctica de la autonomía que buscan convertirse en una alternativa al desencanto de los mismos procesos generados en la arena política oficial (Martínez, 2006, p. 216).

De este modo, estas organizaciones ofrecen un vínculo con una diversidad de organizaciones, demostrando la heterogeneidad que presenta y constituye al Movimiento Zapatista. A su vez, en la lucha por generar una construcción paralela a la formal-legal, encuentran en estas instituciones una alternativa realmente democrática al régimen político mexicano, basadas en una práctica política comunitaria y en un ejercicio horizontal del poder, llevando a la praxis el quiebre establecido con los mecanismos institucionales

y tradicionales ofrecidos por la democracia liberal, resignificando con ello la praxis política.

De manera resumida, se puede constatar que las JBG y los Caracoles surgen con motivo de «llevar a la práctica sus ideas de gobierno autónomo, y evitar seguir recibiendo limosnas y/o la imposición de proyectos externos por parte de la sociedad civil nacional e internacional» (Martínez, 2006, p. 218), es decir, se articulan como base material del discurso.

\section{El principio de «mandar obedeciendo»}

La particularidad de las JBG y los Caracoles reside en el principio de «mandar obedeciendo», pues con esto la política no es vista en un sentido tradicional, sino que se encuentra cargada de un sentido ético:

La idea de la política vinculada a la ética [...] rebasa y quiebra completamente la noción de la política, separada y vaciada de lo ético, de lo social y de lo histórico, y que afirma cínicamente que «el fin justifica todos los medios», auto concibiéndose además como 
una actividad supuestamente muy compleja y sofisticada, donde los pocos, las élites, los políticos profesionales, detentan el monopolio de un mando despótico y prepotente, y los muchos, los subalternos, los ciudadanos de a pie, se ven forzados a obedecer (Aguirre, 2010, p. 67).

Esto se comprende si se pone de manifiesto que la concepción moderna de la política se encuentra estrictamente ligada a una noción de poder que se articula con determinadas estructuras, dispositivos y orden, puesto que:

La política sería, así, para nosotros: aspiración a la participación en el poder, o a la influencia sobre la distribución del poder, ya sea entre Estados o, en el interior de un Estado [...]. Cuando se dice que una cuestión es una cuestión política, [...] entonces se entiende siempre con ellos que los intereses de la distribución, la conservación o el desplazamiento del poder son determinantes de la respuesta a aquella cuestión (Weber, 2005, p. 1056).

En este sentido, al poder tradicionalmente se le ha entendido de manera negativa, ya que se vincula a ciertos tipos de coerción. Es así como el poder, en su expresión política, se concibe como la «probabilidad de que un actor dentro de una relación social esté en posición de realizar su propia voluntad, a pesar de las resistencias, independientemente de las bases en que resida tal probabilidad» (Weber citado en Bouza-Brey, 1999, p. 40). Por lo tanto, cabe destacar que el poder posee dos características generales en su sentido tradicional: en primer término, es un fenómeno relacional, es decir, debe haber más de un individuo para que exista una relación de poder; en segundo lugar, la relación de poder es asimétrica (Montbrun, 2010, p. 370). Debido a esto, se tiene que pensar al poder desde una perspectiva de mandoobediencia, ya que no todas las partes relacionadas poseen la capacidad de ejercer el poder. Por su parte, el principio de «mandar obedeciendo», al vincularlo al campo de la ética, realiza un giro radical en relación con la concepción moderna de política y poder, puesto que se hace necesario observarlo desde una óptica normativa:

Mandar-obedeciendo —-sabe que no sabe-, a diferencia del poder en el gobierno, que simula saber el saber y que si bien no sabe que no sabe nada [...]. El poder representa entonces, para el zapatismo un problema político por ético, pues el discurso simulado ejerce la violencia imponiendo su voluntad [...], bajo la máscara de una doctrina moralizante que postula saber lo que es bueno para todos, con lo que 
justifica la actitud destructiva que tiene ante todo lo que se opone a él, pues su meta es que nada se mueva, en ello se sostiene la inmovilidad de su certeza (Hernández, 2002, p. 106).

El zapatismo instala así una noción de poder horizontal, es decir, permite verlo de una forma positiva y no coercitiva, donde poseerlo no significa la opresión de un sujeto hacia el otro, sino que se trata de un reconocimiento del otro, bajo un criterio de no-exclusión (Villoro, 2007) entre las diversas partes que se encuentran en esta relación de poder:
Al medirse con el otro, el sujeto ya no se ve simplemente como diferente sino que, al mismo tiempo que afirma su diferencia, proclama su igualdad con el oponente. Es un paso en el establecimiento posible de valores y normas comunes. Pero serían normas que no decretarían ninguna uniformidad entre los adversarios, sino abrirían la posibilidad de reconocimiento recíproco de una igualdad en la facultad de acceder a valores comunes, sin eliminar las diferencias (Villoro, 2007, p. 33).

De esta forma, los zapatistas «aspiran a un replanteamiento de la cultura política en el sentido de una inversión de la pirámide del poder. Su concepción

[ 62 ] de democracia es una sociedad en la que el poder estaría situado en la base y las instituciones, los representantes, los elegidos estarían al servicio de esa base, conforme al principio mandar obedeciendo» (Subcomandante Marcos y Le Bot, 1997, p. 36). Todos sus participantes serían responsables de todo ante todos, ya que al desvincular el poder de su perspectiva reificada la política se entendería en un sentido inverso al juego político tradicional, donde el poder es algo que se obtiene y no se produce y (re)produce, provocando que el sujeto se olvide de su propia creación del mundo, perdiendo de su conciencia la dialéctica entre hombre creador y creación, en otras palabras, entre sujeto productor-producido (Berger y Luckmann, 1998).

Muy por el contrario, los zapatistas, al emplear el principio de «mandar-obedeciendo», asimilan la dialéctica enunciada anteriormente, ya que al mandar producen y crean ciertas estructuras, siendo al mismo tiempo producidos, puesto que obedecen. En este sentido, se puede observar que el Movimiento Zapatista posee conciencia de que aún ante un mundo objetivado, el mundo social ha sido modelado por el ser humano $y$, por tanto, puede ser remodelado o recreado por él mismo (Berger y Luckmann 1998). 


\section{A modo de conclusión}

Respecto a lo inicialmente planteado, se puede concluir que el Movimiento Zapatista, mediante su producción discursiva y praxis respectivas, ha realizado quiebres significativos en cuanto a ciertas nociones tradicionales del quehacer político, en especial sobre lo que se entiende por política y poder, puesto que mediante su discurso político, basado en aspectos éticos, ha procurado acentuar la creación de nuevos símbolos, mostrando desde una perspectiva crítica la arbitrariedad y la violencia del discurso dominante, ya que este se ha encargado de imposibilitar cualquier alternativa de forma de vida, mermando con ello la heterogeneidad y diversidad de mundos existentes.

Bajo la misma línea, el Movimiento Zapatista posee conciencia de que la creación de la realidad es el resultado de la producción del ser humano y que para objetivarla es imprescindible la utilización del lenguaje y ciertas funciones de este. Cabe destacar que, además de su producción discursiva, los zapatistas han generado sus propias instituciones, las cuales han permitido poner de manifiesto que la política, el poder y la democracia se pueden ejercer de manera diferente, y para ello el discurso ha sido una herramienta fundamental de legitimación.

Sin embargo, resulta primordial señalar que el quiebre en torno a las acepciones señaladas se produce cuando los zapatistas logran resignificar y reinterpretar ciertos símbolos, los cuales se pueden observar en la materialidad del funcionamiento de las Juntas del Buen Gobierno y los Caracoles. Estos cambios estructurales en un territorio determinado han sido modificados desde lo discursivo y no como lo plantean las teorías tradicionales de cómo realizar una revolución, las cuales apuntan a la apropiación de los lugares que representan al poder por excelencia, por ejemplo, el Estado. Por otro lado, se debe considerar que el poder en general y el poder político en particular se encuentran estrechamente vinculados a la política; no obstante, es menester apreciar que las nociones tradicionales de estos conceptos se han presentado a partir de una forma vertical y excluyente, para lo cual el Movimiento Zapatista desde su producción discursiva logra invertir dichas nociones, ya que el poder es visto desde una representación horizontal y no jerárquica, y la política como un lugar inclusivo, diverso y heterogéneo. Este nuevo quehacer político es abordado desde componentes normativos, convirtiendo ciertos principios como símbolos propios del discurso zapatista. 
Se destaca que el principio de «mandar-obedeciendo» permite resignificar las nociones de política y poder, generando de manera paralela una reconfiguración y cambio en las nociones de organización, puesto que tal principio constitutivo y deontológico permite la realización de un sujeto productor-producido, poniendo en cuestión la clásica discusión dicotómica en la que se plantea que el sujeto se encuentra determinado por la estructura o que este la determina. De manera contraria, en el discurso zapatista, en especial en el principio descrito, se reconoce la relación dialéctica que se genera, lo cual ha sido un factor fundamental para trastocar las nociones tradicionales de la política y el poder, ya que reconocen que la realidad y la sociedad es un «producto humano» (Berger y Luckmann, 1998, p. 84), confrontando con ello las concepciones reificadas de la política y de los marcos instituciones que la cobijan.

\section{Referencias bibliográficas}

1. Aguirre, Carlos Antonio. (2010). La mirada neozapatista: mirar (hacia y desde) abajo y a la izquierda. Revista Rebeldía, (8) 68, pp. 61-72.

2. Ansart, Pierre. (1983). Ideologías, conflicto y poder. México, D. F.: Premia.

3. Berger, Peter y Luckmann, Thomas (coords.). (1998). La construcción social de [ 64 ] la realidad. Buenos Aires: Amorrortu.

4. Bouza-Brey, Luis. (1999). El poder y los sistemas políticos. En: Caminal Badía, Miquel (coord.). Manual de Ciencia Política. Madrid: Tecnos.

5. Ejército Zapatista de Liberación Nacional (EZLN). (2005, junio 21). Carta a la sociedad civil nacional e internacional. Recuperado de https://palabra.ezln.org.mx/ comunicados/2005/2005_06_21.htm

6. Ejército Zapatista de Liberación Nacional (EZLN). (2011, enero-febrero). Carta primera (completa) del SCI Marcos a Don Luis Villoro. Las 4 partes del texto Apuntes sobre las guerras, inicio del intercambio epistolar sobre Ética y Política. Enlace Zapatista. Recuperado de https://enlacezapatista.ezln.org.mx/2011/03/09/apuntessobre-las-guerras-carta-primera-completa-del-sci-marcos-a-don-luis-villoro-inicio-delintercambio-epistolar-sobre-etica-y-politica-enero-febrero-de-2011/

7. Firedmann, Reinhard. (2010). El pensamiento postmoderno. buscar líneas de fuga o la pasión del pensar. Buenos Aires: Universidad Nacional de Quilmes.

8. Foucault, Michel. (2008). Un diálogo sobre el poder y otras conversaciones. Madrid: Alianza.

9. Godoy, Oscar. (1994). Antología del pensamiento de Maquiavelo. Revista Estudios Públicos, 53, pp. 389-424.

10. Hernández, Laura. (2002). Detrás de nosotros estamos ustedes. La ironía en el discurso del subcomandante Marcos. Signos Literarios y Lingüísticos, 4 (2), pp. 101-115. 
11. Holloway, John. (2001). El zapatismo y las ciencias sociales en América Latina. Revista OSAL, 4, pp. 171-176.

12. Holloway, John. (2011). Cambiar el mundo sin tomar el poder. El significado de la revolución hoy. Santiago: LOM.

13. Huffschmid, Anne. (2009). De los cuerpos al corpus. Una experiencia de investigación en torno al discurso zapatista y sus ecos en el mundo. Berlín: Instituto de Estudios Latinoamericanos.

14. Lazo, Jorge. (2004). Ideología y anti-globalización: Una aproximación al discurso de la vía campesina. Revista de Ciencia Política, xxıv (1), pp.169-188. http:// dx.doi.org/10.4067/S0718-090X2004000100007

15. Leyva, Xóchitl. (1999). De las cañadas a Europa: niveles, actores y discurso del Nuevo Movimiento Zapatista (1994-1997). Revista Desacatos, 1, pp. 1-25.

16. Marsh, David y Stoker, Gerry. (1997). Teoría y métodos de la ciencia política. Madrid: Alianza.

17. Martínez, Manuel. (2006). Las Juntas de Buen Gobierno y los Caracoles del Movimiento Zapatista: Fundamentos analíticos para entender el fenómeno. Revista de Investigaciones Políticas y Sociológicas, 5 (1), pp. 215-233.

18. Martínez, Manuel. (2007). Derechos indígenas en América Latina. Emergencia política, autonomía y zapatismo. Temas y Debates, 13. https://doi.org/10.35305/tyd. v0i13.139

19. Montbrun, Alberto. (2010). Notas para una revisión crítica del concepto de poder. Polis, 9 (25), pp. 367-389. http://dx.doi.org/10.4067/S071865682010000100022

20. Parra, Marcela. (2005). La construcción de los movimientos sociales como sujetos de estudio en América Latina. Athenea Digital, 8, pp. 72-94. https://doi. org/10.5565/rev/athenead/v1n8.220

21. Subcomandante Marcos y Le Bot, Yvon. (1997). El sueño zapatista. El Ortiba. Recuperado de http://www.elortiba.org/old/pdf/suenio-zap.pdf

22. Tomassini, Luciano. (2010). Rompiendo códigos. El cambio cultural de nuestro tiempo. Santiago: Consejo de la Cultura, Flacso.

23. Touraine, Alain. (1995). Producción de la sociedad. México, D. F.: IFAL.

24. Van Dijk, Teun. (2009). Discurso y poder. Contribuciones a los estudios críticos del discurso. Barcelona: Gedisa.

25. Villoro, Luis. (2007). Los retos de la sociedad por venir. Ensayos sobre justicia, democracia y multiculturalismo. México, D. F.: Fondo de Cultura Económica.

26. Weber, Max. (2005). Economía y sociedad. México, D. F.: Fondo de Cultura Económica.

27. Zapatista Organización. (2014, 28 de noviembre). Zapatistas - Crónica de una Rebelión [Archivo de video]. Recuperado de https://www.youtube.com/ watch $?$ v $=$ Kcy5M72ioak\&has_verified $=1 \&$ bpctr $=1590440821$ 